\title{
Thermal-Electrical Analogy for Dynamic Urban-Scale Energy Modeling
}

\author{
Guglielmina Mutani ${ }^{1 *}$, Valeria Todeschi ${ }^{2}$, Michele Pastorelli $^{3}$ \\ ${ }^{1}$ Department of Energy, R3C, corso Duca degli Abruzzi 24, Torino10129, Italy \\ ${ }^{2}$ Department of Energy, FULL, corso Duca degli Abruzzi 24, Torino 10129, Italy \\ ${ }^{3}$ Department of Energy, corso Duca degli Abruzzi 24, Torino 10129, Italy
}

Corresponding Author Email: guglielmina.mutani@polito.it

https://doi.org/10.18280/ijht.380301

Received: 20 June 2020

Accepted: 30 July 2020

\section{Keywords:}

building energy balance, hourly model, residential buildings, urban scale, urban variables, thermal-electrical analogy, placebased analysis

\begin{abstract}
The development of urban-scale energy modeling is currently the goal of many research groups as a result of to the increased interest in evaluating the impacts of energy efficiency measures in cities. These energy models are useful to explore consumption and emission distribution at district scale and to quantitatively assess renovation strategies and energy supply options.

This work presents a dynamic energy modeling based on an energy-balance of residential buildings which uses urban-scale data. The model was designed to take into account the microclimate conditions and morphological urban-scale parameters. This methodology was calibrated, optimized and validated by applying it to a district in the city of Turin. In addition, a thermal-electricity analogy has been implemented in a software for scientific computation and simulation to manage big database. Therefore, a new model based on thermal-electrical analogies, which can be applied to a larger building stock, is presented. A sensitivity analysis has highlighted the different types of behavior of building considering their periods of constructions. The results of this work show that this model can also be applied at a district scale with good accuracy, especially for old buildings, to manage the existing large databases for analyses at an urban or territorial scale; for newer buildings needs to be improved.
\end{abstract}

\section{INTRODUCTION}

A reduction in energy consumption in buildings could be one of the main drivers considered to improve the energy sustainability and quality of urban environments, in order to exploit the production of energy from the available renewable sources [1].

In this context, the urban-scale energy models (USEM) are useful to explore the consumption, production and productivity of buildings at a territorial scale in order to achieve the energy security [2, 3]. Since the relationship between urban form and buildings affects the energy performances of buildings, these models can be used to obtain a lower energy demand by improving the morphology of the built environment [4]. So far, USEMs have only considered few variables that are known to influence consumption, especially as regards the urban context.

The novelty of the energy model presented in this work is that a number of urban variables have been added to the energy balance to take into account the surrounding context: solar exposition, urban canyon height-to-distance ratio, characteristics of outdoor spaces, and the presence of vegetation [5].

Recently an 'engineering' model was developed for the city of Turin (IT), with the support of Geographical Information System and Google Earth tools, in order to create an urban energy atlas for the building stock [3]. In this work, that model has been improved by moving from monthly to hourly consumption data and introducing a thermo-electrical analogy.
The aim of this work has been to create a platform that may be used by stakeholders, energy producers and distributors, urban planners and policy makers to plan smart energy systems and sustainable cities, and to obtain information, at different scales, about energy consumption, production and emissions. With this engineering model, it will also be possible to evaluate how energy consumption changes according to the energy efficiency level and system efficiency of a building, but also according to urban morphology [6]. The goal of this platform is to guarantee energy security, affordability and environmental sustainability for more resilient cities $[7,8]$.

\section{MATERIAL AND METHODS}

This work introduces an hourly urban-scale energy model of residential buildings together with a thermal-electricity analogy.

The used methodology is based on the existing ISO 520161:2017 and ISO 52017:2017 standards which describe the energy balance equations that can be applied to a single building. In this work, these equations have been simplified considering the available buildings data for the city of Turin, using existing georeferenced databases such as technical maps, the reference territorial database, a digital territorial model, a digital surface model and data from the population and housing census for the year 2011. All cities have this data and therefore this analysis can be easily replicable. A GIS tool has been used to identify all the characteristics of the buildings that influence their consumption for space heating. 


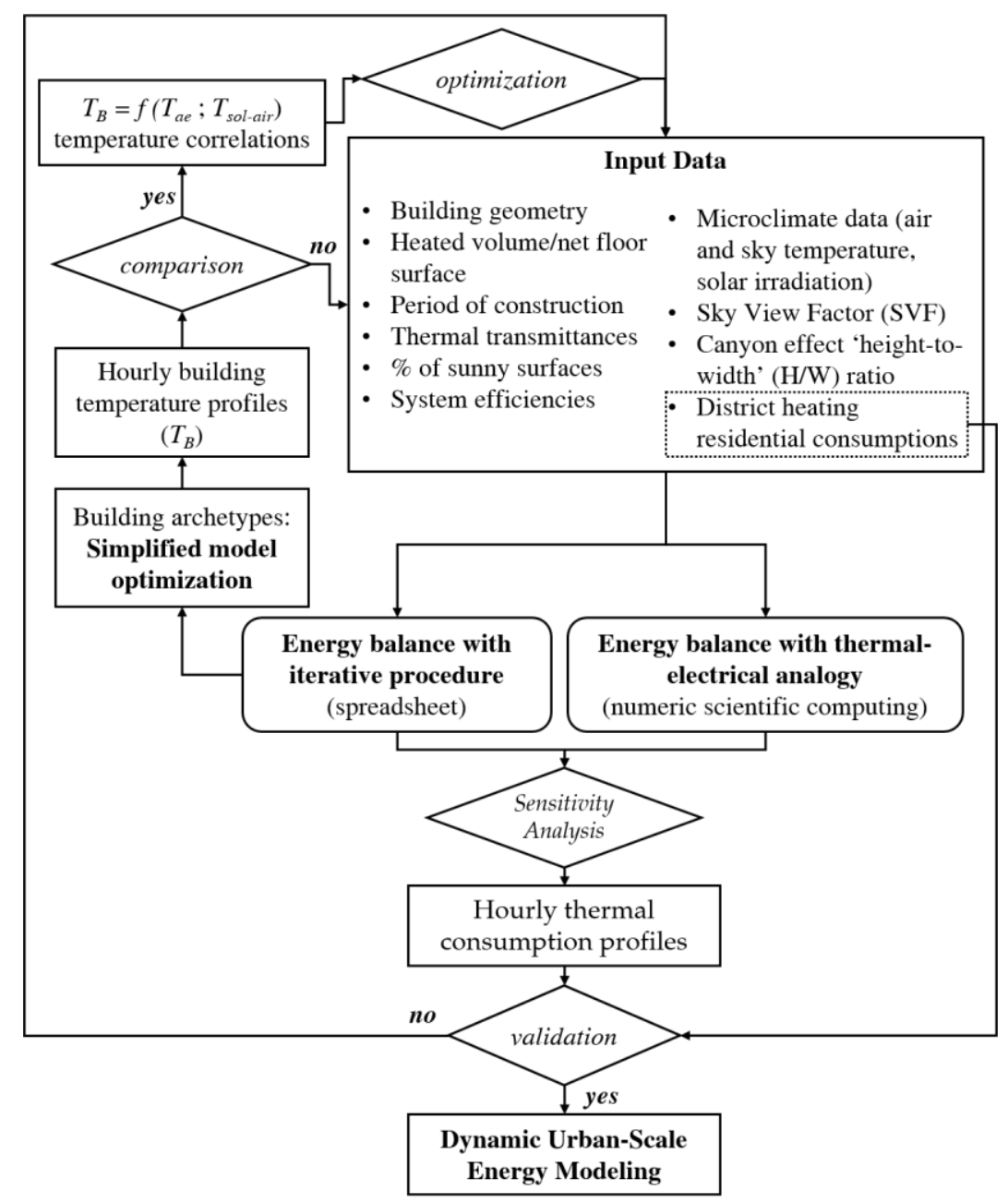

Figure 1. Flowchart of methodology

The thermal-electrical model has been implemented with the support of Matlab considering the input data previously identified for the different building typologies and local climate conditions [9].

The accuracy of the energy balance model has been evaluated by comparing the calculated and measured energy consumptions for space heating on about 100 residential buildings in Turin for the 2013-14 and 2014-15 heating seasons. In the first part of the work, a daytime temperature of the buildings was set equal to the winter comfort conditions (i.e. $20 \pm 2^{\circ} \mathrm{C}$ ).

The building temperature was then corrected to reduce the model errors, considering the main local climatic variables that influence energy consumption. The accuracy of the model was improved with this optimization.

Figure 1 describes the methodology used to design the dynamic urban-scale energy model: the main input data; the iterative procedure; the identification of building archetypes by construction periods; the analysis of hourly temperatures profiles; the model optimization with the identification of correlations between the buildings temperature and the local climate conditions; the thermal-electrical analogy process; and the model validation.

\subsection{Energy balance model}

In the first part of the analysis, input data were selected considering the data available for residential buildings at an urban scale. Some missing variables, such as the solar shadings, the view factors and building orientations were calculated at a block of building scale and were then associated with each building.

Subsequently, each building was subdivided into three thermodynamic systems:

- the inside part of the building with air, internal partitions, furniture, people and objects: called B - building;

- the opaque envelope that separates the inside part of the building from the outside, unheated and other heated environment: called E - envelope;

- the transparent elements that separates the inside part of the building from the outside environment: called $\mathrm{G}$ - glazing.

This model has concentrated parameters and the three thermodynamic systems exchange heat with each other. Moreover, the heat supplied to the building is known and there are three equations for the three unknowns that are the temperatures of the three thermodynamic systems (TS).

The energy balance equation used for the three TSs is the following:

$$
C_{T S} \frac{d T_{T S}}{d t}=\emptyset_{s o l}+\emptyset_{I}+\emptyset_{H}-\left(\emptyset_{T}+\emptyset_{V}\right)
$$

where: $C$ is the heat capacity $\left[\mathrm{JK}^{-1}\right], T$ is the temperature $[\mathrm{K}], t$ is the time [s], $\phi_{\text {sol }}$ is the heat flow rate from solar gains [W], $\phi_{I}$ is the heat flow rate from internal gains, $\phi_{H}$ is the heat flow rate from the heating system, $\phi_{T}$ is the heat flow rate dispersed by transmission, $\phi_{V}$ is the heat flow rate dispersed by ventilation.

The three energy balance equations were solved for each 
hour, through an iterative method, by setting a maximum number of 100 iterations and an acceptable error of 0.001 .

The main assumptions on which this model is based are as follows:

(1) the buildings are thermal zones with a uniform temperature,

(2) the heat flow is unidirectional (and thermal bridges were neglected) and is calculated through a heat exchange coefficient,

(3) the latent heat for humidification or dehumidification was neglected because residential buildings in Italy have water heating systems (the relative humidity of the air is not controlled)

(4) at daytime in the buildings, the comfort thermal conditions are reached.

The input data and the variables used for the energy balances of the three thermodynamic systems described with Eq. (1) are introduced in the next subsections.

\subsubsection{Heat flow rate from solar gains $\phi_{\text {sol }}$}

The solar heat flow depends on: the characteristics of solar absorbance, reflectance and transmittance characteristics of the opaque and transparent building elements, the sunny areas of the building envelope and the incident solar irradiance.

The solar heat flow can be divided into two components:

(1) the heat flow absorbed by the opaque and transparent envelope element $k$ :

$$
\emptyset_{s o l, \alpha}=\sum \alpha_{k} \cdot I_{s o l} \cdot \xi \cdot F_{k} \cdot A_{k}
$$

(2) the heat flow that enters the building through the envelope element $k$ :

$$
\emptyset_{s o l, \tau}=\sum \tau_{G} \cdot I_{s o l} \cdot \xi \cdot F_{k} \cdot A_{k} .
$$

The solar absorbance $\alpha$ and total transmittance $\tau$ depend on the type of opaque and transparent envelope while the solar irradiance $I_{\text {sol }}$ depends on the climate conditions recorded at the weather stations. Area $A$ of element $k$ was calculated with a GIS tool, using the aforementioned technical map and the digital surface model. In order to evaluate the share of sunny envelope $\xi$, the solar height $\psi$ was calculated using solar geometry:

$$
\begin{gathered}
\psi=\sin ^{-1} \cdot(\sin \varphi \cdot \sin \beta+\cos \varphi \cdot \cos \beta \cdot \cos z) \\
a=\sin ^{-1} \cdot(\cos \beta \cdot \sin z / \cos h) \\
\beta=\sin ^{-1} \cdot\{0.398 \cdot \sin [0.9863 \cdot(d-82)]\} \\
\xi=\left\{\begin{array}{lll}
\frac{\tan (\psi)}{H / W} & \text { if } & h<\arctan (H / W) \\
1 & \text { if } & h \geq \arctan (H / W)
\end{array} .\right.
\end{gathered}
$$

The solar height $\psi$ was evaluated for each hour using Eqns. (4), (5) and (6) and knowing: latitude $\varphi$, solar declination $\beta$, hour angle $z=15(s h-12)$, solar hour $s h$ and day number $d$. The share of the sunny part of the envelope $\xi$ was then evaluated with Eq. (7) knowing the urban canyon geometry (height-towidth ratio $H / W$ ).

The effective share of the sunny part of the envelope takes into account the obstruction factor $F_{k}$ which was evaluated with the sky view factor $(S V F)$ utilizing the Relief Visualization Toolbox.

\subsubsection{Heat flow rate from internal gains $\phi_{I}$}

The internal gains of residential buildings can be evaluated from the average floor area of dwellings $S_{f}$ and the number of dwellings $n$ :

$$
\emptyset_{I}=q_{i n t} \cdot S_{f} \cdot n
$$

while the hourly profiles of $q_{i n t}$ due to occupants and equipment for daytime and nighttime in residential buildings was derived from the UNI/TS 11300-1:2014 and ISO 13790:2008 standards.

\subsubsection{Heat flow rate from the heating system $\phi_{H}$}

The heat flow rate from the heating system was calculated from the energy $\phi_{S, H}$ delivered by the district heating company to the buildings every hour and from the efficiency of the heating system $\eta_{H}$ :

$$
\emptyset_{H}=\emptyset_{S, H} \cdot \eta_{H}
$$

The hourly energy consumptions were calculated by linear interpolation from the cumulative consumptions in order to derive the exact hourly data. The heating in the analyzed buildings is shutdown at night from $10 \mathrm{pm}$ to $5 \mathrm{am}$ and it was assumed, in the thermal model, that once the comfort temperature has been reached, the system shuts down.

\subsubsection{Heat flow rate by transmission $\phi_{T}$}

The heat flow dissipated by transmission, $\emptyset_{T}$, through the opaque and transparent envelope towards the outside environment (or other unheated environments) depends on area $A$, the thermal resistance $R$ of the dispersing elements and the temperature gradients:

$$
\begin{aligned}
& \emptyset_{T, t}=\sum \frac{A_{k}}{\frac{1}{2} \cdot R_{k}+R_{s e}} \cdot b \cdot\left(T_{T S}-T_{a e}\right) \\
& -\sum \frac{A_{k}}{\frac{1}{2} \cdot R_{k}+R_{s i}} \\
& \cdot\left(T_{T S}-T_{B}\right) \cdot \emptyset_{H}=\emptyset_{S, H} \cdot \eta_{H}
\end{aligned}
$$

The correction coefficient $b$ is used if the heat flow is dissipated by transmission to an unheated environment ( $b=1$ to the external environment).

Moreover, the extra heat flow, due to thermal radiation lost to the sky $\phi_{T, r}$ by the building envelope, was added:

$$
\emptyset_{T, r}=\sum F_{r} \cdot R_{s e} \cdot U_{k} \cdot A_{k} \cdot h_{r, k} \cdot\left(T_{a e}-T_{s k y}\right) .
$$

where: the form factor building-sky $F_{r}$ was evaluated with the sky view factor $(S V F)$ and the view factor (that depends on the control surface inclination); $R$ and $U$ are the thermal resistances and transmittances; $h_{r}$ is the radiative heat transfer coefficient between the envelope area $A$ of element $k$ and the sky.

\subsubsection{Heat flow rate by ventilation $\phi_{V}$}

The heat flow dissipated by ventilation $\emptyset_{V}$ was estimated from the specific heat of the air $c_{a}$, the temperature gradient 
between the inside and outside air and the air mass flow rate $\dot{m}_{a}$ (knowing the air changes per hour ach [10], the air density and the air volume):

$$
\emptyset_{V}=c_{a} \cdot \dot{m}_{a} \cdot\left(T_{a i}-T_{a e}\right)
$$

The ach, for residential buildings, can be estimated as 0.3 $0.5 \mathrm{~h}^{-1}$ depending on the type of windows and on the maintenance status of the building [3].

\subsection{Thermal-electrical analogy}

The energy balance of the buildings was described by means of thermal-electrical analogy, using a scientific numerical computational program. This process is fundamental when the model is applied at an urban scale because it allows the consumption of a large number of buildings to be managed and calculated [11].

The thermal-electrical analogy process is based on the similarity shown by the equations that model the heat transfer among systems and the equations that model the electric current flow in a circuit $[12,13]$. Like other analogies adopted in the field of engineering (i.e. hydraulic-electrical and electrical-mechanical-acoustical analogies), it allows the schematics of system to be drawn using well known international electric symbols Simulation programs, specifically developed for electric networks to be used to solve thermal system. Some tools already consider the thermalelectrical analogy, but at block of building scale, not at an urban scale. For example, CitySim is based on thermalelectrical analogy, where the heat flow between walls and the external air temperature can be represented by an electrical current through a resistor, and the inertia of wall is the capacitance [14].

If a mono-dimensional heat transfer is considered, the heat transferred to a thermal conductor is proportional to the difference in temperature at the end of the conductor by a proportionality constant that is equal to the thermal conductance $(Y)$. Analogously, the electric current in an electric conductor is proportional to the voltage drop across its terminals, and the proportionality constant is equal to the electric conductance.

The heat flow in a body that is able to store energy is proportional to its temperature derivative by a constant, that is, the thermal capacity $(C)$, while the electric current in a capacitor is proportional to the voltage derivative across its terminal, and the proportionality constant is equal to the electric capacitance.

Table 1. Electrical - thermal analogy: Components

\begin{tabular}{|c|c|c|}
\hline Symbols & $\begin{array}{l}\text { Voltage } \\
\text { Current } \\
\end{array}$ & $\begin{array}{c}\text { Temperature } \\
\text { Heat Flow }\end{array}$ \\
\hline & Electrical resistance; & Thermal resistance; \\
\hline & $\begin{array}{l}\text { Electrical conductance } \\
\text { time invariant }\end{array}$ & $\begin{array}{c}\text { Thermal transmittance, } \\
\text { time invariant }\end{array}$ \\
\hline & Electrical resistance; & Thermal resistance; \\
\hline & $\begin{array}{l}\text { Electrical conductance; } \\
\text { time dependent }\end{array}$ & $\begin{array}{c}\text { Thermal transmittance, } \\
\text { time dependent }\end{array}$ \\
\hline & Electrical capacity & Thermal capacity \\
\hline & $\begin{array}{l}\text { Independent voltage } \\
\text { source }\end{array}$ & Independent temperature \\
\hline & $\begin{array}{l}\text { Independent current } \\
\text { source }\end{array}$ & Assigned heat flow \\
\hline
\end{tabular}

A body with a fixed or assigned temperature can be assumed as an independent electric voltage source $(T)$, while a heat flow can be modelized as an independent current source $(I)$.

Starting from the equations that rule the thermal system, an electric network can be defined using the internationally defined electrical symbology and a thermal environment problem can be solved by solving an electric circuit, if the input parameters of the electric circuit have been set properly (Table 1).

The three thermal systems (G, E and B), with reference to Eq. (1), can be represented by an electric circuit with three parallel capacitors connected to three independent current sources, which represent the addition of heat to the system, and are interconnected by resistors. The energy balances used for the three thermodynamic systems are:

$$
\begin{aligned}
& C_{G} \frac{d T_{G}}{d t}=\sum \alpha_{G, k} \cdot I_{s o l, k} \cdot \xi_{k} \cdot F_{k} \cdot A_{G, k} \\
& -\sum \frac{A_{G, k}}{\frac{1}{2} \cdot R_{G, k}+R_{s e}} \cdot\left(T_{G}-T_{a e}\right)+ \\
& -\sum \frac{A_{G, k}}{\frac{1}{2} \cdot R_{G, k}+R_{s i}} \cdot\left(T_{G}-T_{B}\right) \\
& \begin{array}{l}
-\sum_{\left(T_{a e}-T_{s k y}\right)} F_{r} \cdot R_{s e} \cdot U_{G, k} \cdot A_{G, k} \cdot h_{r, G, k} \\
\cdot R
\end{array} \\
& C_{E} \frac{d T_{E}}{d t}=\sum \alpha_{W, k} \cdot I_{s o l, k} \cdot \xi_{k} \cdot F_{k} \cdot A_{W, k} \\
& -\sum \frac{A_{E, k}}{\frac{1}{2} \cdot R_{E, k}+R_{s e}} \cdot b \cdot\left(T_{E}-T_{a e}\right)+ \\
& -\sum \frac{A_{E, k}}{\frac{1}{2} \cdot R_{E, k}+R_{S i}} \cdot\left(T_{E}-T_{B}\right) \\
& -\sum F_{r} \cdot R_{s e} \cdot U_{W, k} \cdot A_{W, k} \cdot h_{r, W, k} \\
& \cdot\left(T_{a e}-T_{s k y}\right) \\
& C_{B} \frac{d T_{B}}{d t}=\sum \tau_{G, k} \cdot I_{s o l, k} \cdot \xi_{k} \cdot F_{k} \cdot A_{G, k}+\emptyset_{\mathrm{I}}+\emptyset_{H} \\
& -\sum \frac{A_{E, k}}{\frac{1}{2} \cdot R_{E, k}+R_{s i}} \cdot\left(T_{B}-T_{E}\right)+ \\
& -\sum \frac{A_{G, k}}{\frac{1}{2} \cdot R_{G, k}+R_{s i}} \cdot\left(T_{B}-T_{G}\right)-c_{a} \cdot m_{a} \cdot\left(T_{a i}-T_{a e}\right)
\end{aligned}
$$

An independent voltage source, which represents the external ambient temperature value, is also present in the circuit (Figure 2).

If the heat flow through ventilation, with variable infiltrations and window openings, is neglected, the electric circuit is a circuit with constant impedances (the resistor and capacitor values are not affected by the time) and with independent current and voltage sources that are time dependent. This kind of network is usual in electrical engineering and can be analyzed by considering the superposition effect: each generator in the circuit is considered individually and the currents/voltages produced by each generator are then summed.

If the heat flow through ventilation, with variable infiltrations and window opening, is considered, a time dependent resistance (or conductance) is introduced into the circuit. According to this assumption, the symbolic 
representation cannot be used, and the system requires the system of differential equations to be numerically solved.

The specificity of the electric circuit that is equivalent to the adopted thermal model (described with Eqns. (13), (14), (15) for the three thermodynamic systems $\mathrm{G}, \mathrm{E}$ and $\mathrm{B}$ ) is that the time variant parameter is the value of a conductance in a closed network, where the conductance itself is in series with an independent current source and a voltage source (Figure 2 and Table 2). This allows a simplified method to be adopted in the solution of the circuit.

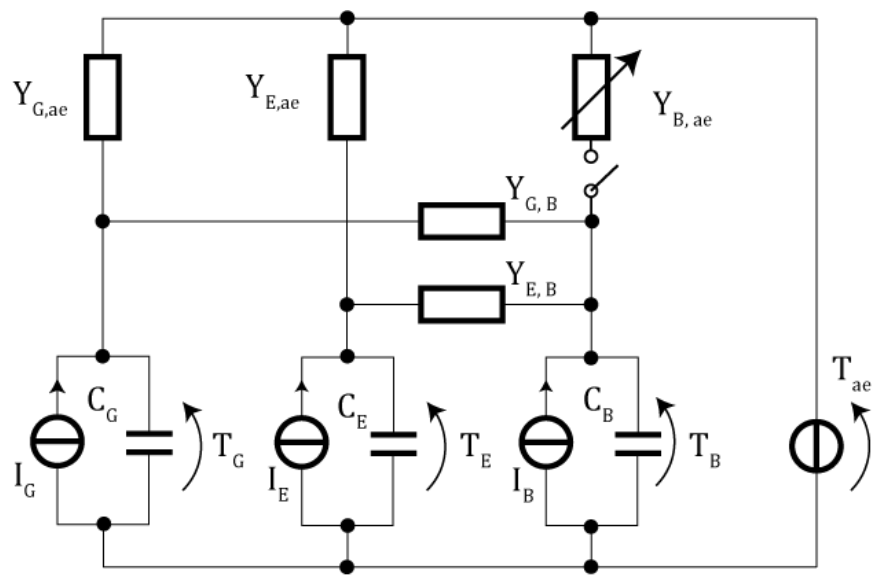

Figure 2. The thermal-electrical analogy process

Table 2. Electrical model parameters and reference to Eqns. (13), (14), (15)

\begin{tabular}{cc}
\hline Var. & Thermal balance components \\
\hline$I_{G}$ & $\sum \alpha_{G} \cdot I_{s o l} \cdot \xi \cdot F \cdot A_{G}-\sum F_{r} \cdot R_{s e} \cdot U_{G} \cdot A_{G} \cdot h_{r, G} \cdot\left(T_{a e}-T_{s k y}\right)$ \\
$Y_{G, a e}$ & $\sum \frac{A_{G}}{1} R_{G}+R_{s e}$ \\
$Y_{G, B}$ & $\sum \frac{A_{G}}{1} R_{G}+R_{S i}$ \\
$I_{E}$ & $\sum \alpha_{E} \cdot I_{s o l} \cdot \xi \cdot F \cdot A_{E}-\sum F_{r} \cdot R_{s e} \cdot U_{E} \cdot A_{E} \cdot h_{r, E} \cdot\left(T_{a e}-T_{s k y}\right)$ \\
$Y_{E, a e}$ & $\sum \frac{A_{E}}{1} R_{E}+R_{S e}$ \\
$Y_{E, B}$ & $\sum \frac{A_{e}}{1} R_{E}+R_{S i}$ \\
$I_{B}$ & $\phi_{H}+\phi_{I}+\sum \frac{\tau_{G} \cdot I_{s o l} \cdot \xi \cdot F \cdot A_{G}}{Y_{B, a e}}$ \\
\hline
\end{tabular}

A common problem is the estimation of the energy consumption of a building, or a group of buildings, with assigned weather conditions, before it is (or they are) connected to the DH network. Weather conditions are generally non-period functions, but it is usual to predict the consumption by referring to standard days, which are defined considering the local climate conditions in the specific location. In this case, the consumptions were computed assuming that the local climate conditions were equal to a long series of reference days, thus the consumptions could be evaluated from the Fourier series and using the symbolic method.

Considering that there are thermal valves on each heat exchanger, which regulate the water flow in order to maintain the temperature in the living volume of the building at a constant value, as set by the user, the consumptions can be estimated in two steps.

The consumptions for an assigned indoor temperature can initially be evaluated without considering window ventilation. Then, considering that the time variant thermal conductivity is in a closed network series connected to an independent current source and a voltage source, the heat flow due to ventilation can easily be computed (the indoor temperature is an input value and the external temperature is a constraint). The additional consumptions following ventilation are then added to the previous value computed without considering ventilation.

In this way, a simple and quick algorithm that does not require numerical integration is used.

\subsection{Optimization and validation}

The model was validated by considering the different contributions to the energy balance equations and then comparing the consumptions calculated by the model with the measured consumptions. A comfortable building temperature of $20 \pm 2{ }^{\circ} \mathrm{C}$ was assumed during the day (from 8 a.m. to 9 p.m.) to calculate energy consumption.

In order to improve the accuracy of the model results, it was assumed that the building temperature could vary depending on outdoor local climatic conditions and in particular on the sun-air temperature, which takes into account the contribution of air temperature and solar radiation.

\section{CASE STUDY}

Turin is located in the northwestern part of Italy and it has a continental temperate climate. In Turin, residential buildings are mainly large and compact condominiums, and $80 \%$ of them were built before 1970 [15]. In order to evaluate the accuracy of the hourly model on residential buildings, the model was applied to a neighborhood with about 100 residential buildings. These buildings described the typical characteristic of the building heritage of the city.

\subsection{Buildings characteristics}

Buildings can be described with geometrical and typological characteristics for energy performance evaluations. Geometrical characteristics were elaborated with a GIS tool from maps and territorial information. The thermo-physical characteristics of a building can be identified according to its period of construction (UNI/TR 11552, [16]).

In this work, some of the characteristics of the buildings in Turin were elaborated from a survey on more than 125,000 energy performance certificates (EPC) released in the 20092015 period for the city of Turin [17]. The median values of the energy-related variables are reported in Table 3, where they are subdivided according to the periods of construction of the buildings. It is possible to observe that the level of efficiency of the considered buildings (with thermal transmittances $U$ and $E P$ ) and heating systems (with heating system efficiencies $\eta_{H}$ and $E P$ ) begins to improve for the buildings in the 1971-80 period and in particular for the last three construction period classes.

The results of an EPC survey on buildings after energy retrofitting interventions are reported in Table 4. Lower energy performance indexes $(E P)$ and lower thermal transmittances $(U)$ and higher values of system efficiencies $\left(\eta_{H}\right)$ can be observed. 
Table 3. EPC for generic reasons (median values)

\begin{tabular}{ccccccccccc}
\hline \multirow{2}{*}{ Period of construction } & $\begin{array}{c}\text { n.EPC } \\
-\end{array}$ & $\begin{array}{c}\mathbf{S n} \\
\mathbf{m}^{\mathbf{2}}\end{array}$ & $\begin{array}{c}\mathbf{V g} \\
\mathbf{m}^{\mathbf{3}}\end{array}$ & $\begin{array}{c}\mathbf{S} / \mathbf{V} \\
\mathbf{m}^{\mathbf{2}} / \mathbf{m}^{\mathbf{3}}\end{array}$ & $\begin{array}{c}\text { Uop } \\
\mathbf{W} / \mathbf{m}^{\mathbf{2}} / \mathbf{K}\end{array}$ & $\begin{array}{c}\mathbf{U w} \\
\mathbf{W} / \mathbf{m}^{\mathbf{2}} / \mathbf{K}\end{array}$ & $\begin{array}{c}\mathbf{U g} \\
\mathbf{W} / \mathbf{m}^{\mathbf{2}} / \mathbf{K}\end{array}$ & $\begin{array}{c}\boldsymbol{\eta} \mathbf{H} \\
-\end{array}$ & $\begin{array}{c}\mathbf{E P h} \\
\mathbf{k W h} / \mathbf{m}^{\mathbf{2}}\end{array} \mathbf{\mathbf { k W h } / \mathbf { m } ^ { \mathbf { 2 } }}$ \\
\hline $\mathbf{1 9 1 9}$ & 19184 & 53.4 & 220.0 & 0.41 & 1.22 & 3.53 & 3.91 & 0.67 & 176.3 & 214.6 \\
$\mathbf{1 9 1 9 - 4 5}$ & 21038 & 52.5 & 213.4 & 0.42 & 1.25 & 3.96 & 4.44 & 0.66 & 187.0 & 226.3 \\
$\mathbf{1 9 4 6 - 6 0}$ & 37875 & 57.0 & 219.8 & 0.38 & 1.15 & 4.23 & 4.79 & 0.66 & 173.0 & 215.5 \\
$\mathbf{1 9 6 1 - 7 0}$ & 27544 & 65.8 & 249.5 & 0.37 & 1.15 & 4.45 & 5.06 & 0.67 & 167.1 & 209.8 \\
$\mathbf{1 9 7 1 - 8 0}$ & 5267 & 76.0 & 289.0 & 0.36 & 1.15 & 4.32 & 4.90 & 0.69 & 159.6 & 200.4 \\
$\mathbf{1 9 8 1 - 9 0}$ & 1635 & 75.0 & 267.4 & 0.45 & 1.07 & 3.00 & 3.25 & 0.68 & 149.2 & 180.8 \\
$\mathbf{1 9 9 1 - 0 5}$ & 4891 & 71.6 & 255.1 & 0.43 & 0.64 & 2.79 & 2.99 & 0.70 & 104.0 & 131.8 \\
$\mathbf{2 0 0 6 - 1 5}$ & 3662 & 62.8 & 239.5 & 0.50 & 0.39 & 1.86 & 1.83 & 0.83 & 59.9 & 82.9 \\
\hline
\end{tabular}

Table 4. EPC after retrofitting interventions (median values)

\begin{tabular}{|c|c|c|c|c|c|c|c|c|c|c|}
\hline Period of construction & $\begin{array}{c}\text { n.EPC } \\
-\end{array}$ & $\begin{array}{l}\text { Sn } \\
\text { m }^{2}\end{array}$ & $\begin{array}{l}\mathrm{Vg} \\
\mathrm{m}^{3}\end{array}$ & $\begin{array}{c}\mathbf{S} / \mathbf{V} \\
\mathbf{m}^{2} / \mathbf{m}^{3}\end{array}$ & $\begin{array}{c}\text { Uop } \\
\mathbf{W} / \mathbf{m}^{2} / \mathbf{K}\end{array}$ & $\begin{array}{c}\mathbf{U w} \\
\mathbf{W} / \mathbf{m}^{2} / \mathbf{K}\end{array}$ & $\begin{array}{c}\mathbf{U g} \\
\mathbf{W} / \mathbf{m}^{2} / \mathbf{K}\end{array}$ & $\eta \mathbf{H}$ & $\begin{array}{c}\text { EPh } \\
k W h / m^{2}\end{array}$ & $\frac{\text { EPgl }}{\mathrm{kWh} / \mathrm{m}^{2}}$ \\
\hline$<1919$ & 907 & 79.3 & 342.0 & 0.47 & 1.15 & 2.40 & 2.50 & 0.80 & 126.7 & 157.0 \\
\hline $1919-45$ & 738 & 78.6 & 329.5 & 0.48 & 1.14 & 2.66 & 2.82 & 0.80 & 136.4 & 164.2 \\
\hline 1946-60 & 1368 & 70.3 & 282.8 & 0.48 & 1.08 & 2.96 & 3.20 & 0.78 & 133.3 & 165.9 \\
\hline 1961-70 & 803 & 86.0 & 324.0 & 0.44 & 1.15 & 3.25 & 3.56 & 0.79 & 132.5 & 167.1 \\
\hline 1971-80 & 122 & 155.8 & 582.7 & 0.50 & 1.09 & 3.08 & 3.35 & 0.79 & 134.1 & 155.3 \\
\hline 1981-90 & 59 & 133.5 & 454.0 & 0.61 & 0.64 & 2.40 & 2.50 & 0.77 & 126.2 & 147.8 \\
\hline 1991-05 & 88 & 88.4 & 292.6 & 0.55 & 0.90 & 2.80 & 3.00 & 0.78 & 102.7 & 124.7 \\
\hline 2006-15 & 54 & 68.1 & 248.9 & 0.74 & 0.32 & 1.77 & 1.71 & 0.87 & 63.5 & 83.0 \\
\hline
\end{tabular}

Table 5. Thermal capacities in $\mathrm{Jm}^{-2} \mathrm{~K}^{-1}$ (per $\mathrm{m}^{2}$ of envelope area) for different periods of construction

\begin{tabular}{|c|c|c|c|c|}
\hline $\begin{array}{c}\text { Elements and } \\
\text { TS }\end{array}$ & $<1945$ & $1946-60$ & 1961-70 & $>1971$ \\
\hline Slab above cellar & \multicolumn{4}{|c|}{317,867} \\
\hline Attic slab & \multicolumn{4}{|c|}{434,400} \\
\hline Walls & \multicolumn{2}{|c|}{574,560} & 231,000 & 191,520 \\
\hline E (Envelope) & 495,001 & 510,786 & 285,154 & 235,736 \\
\hline G (Glazing) & \multirow{2}{*}{\multicolumn{4}{|c|}{$\begin{array}{c}7,314 \text { (single glass } 4 \mathrm{~mm})-2 \mathrm{x} \text { (double } \\
\text { glass) } \\
30,496^{*}\end{array}$}} \\
\hline B (Building) & & & & \\
\hline
\end{tabular}

Table 6. Characteristics of the building sample

\begin{tabular}{ccccc}
\hline Data & $\mathbf{1 9 1 9 -}$ & $\mathbf{1 9 4 6 -}$ & $\mathbf{1 9 6 1 -}$ & $\mathbf{1 9 7 1 -}$ \\
& $\mathbf{4 5}$ & $\mathbf{6 0}$ & $\mathbf{7 0}$ & $\mathbf{8 0}$ \\
\hline S/V ratio & 0.28 & 0.27 & 0.28 & 0.35 \\
Gross volume $\left[\mathrm{m}^{3}\right]$ & 6,986 & 5,892 & 5,968 & 12,364 \\
Net heated floor $\left[\mathrm{m}^{2}\right]$ & 1,559 & 1,284 & 1,322 & 2,965 \\
DH consumption $\left[\mathrm{kWh} / \mathrm{m}^{3} / \mathrm{y}\right]$ & 30.74 & 28.84 & 26.15 & 22.44 \\
$\mathrm{C}_{\mathrm{E}}[\mathrm{kJ} / \mathrm{K}]$ & 779,146 & 659,224 & 380,845 & 839,254 \\
$\mathrm{C}_{\mathrm{G}}[\mathrm{kJ} / \mathrm{K}]$ & 1,731 & 1,327 & 1,367 & 3,118 \\
$\mathrm{C}_{\mathrm{B}}[\mathrm{kJ} / \mathrm{K}]$ & 47,539 & 39,158 & 40,325 & 90,406 \\
No. of dwellings & 20 & 10 & 14 & 33 \\
Heated surface of dwellings & 77 & 118 & 97 & 97 \\
Sn/dw $\left[\mathrm{m}^{2} / \mathrm{dw}\right]$ & & & &
\end{tabular}

The heat capacity $(C)$ of the typical envelope elements and thermodynamic systems as defined in UNI/TR 11552:2014 are shown in Table 5. The last rows in the table indicate the thermal capacities that can be adopted for the three thermodynamic systems. Only the internal part of the building consisting of the internal air, furniture and partitions is considered for the thermodynamic system B. This value was determined considering that the internal part of the building with the first $10 \mathrm{~cm}$ of envelope has a thermal capacity of 165 $\mathrm{kJ} / \mathrm{m}^{2} / \mathrm{K}$ (UNI/TS 11300-1:2014).

These thermal transmittances, heat capacities and system efficiencies values were used to characterize the type of envelope and heating system in the components of the thermal balances in Eqns. (13), (14) and (15).

The results of the application of the thermal-electrical analogy to four typical buildings of different construction periods called "archetypes" are reported in this work. These buildings were chosen from among 92 buildings in a central high-density area in Turin with buildings connected to the district heating network (with night shutdown of the heating system). It can be seen, in Table 6 , that these residential condominiums are compact buildings with low form factors and a decreasing heating consumption for newer buildings. This is obviously just an average consumption, because the presented model is only based on the period of construction of the buildings and the information on retrofitting interventions was obtained from the EPC database, which only mentioned $3.4 \%$ of the buildings in Turin.

The first part of the analysis consisted of an analysis of the consumption profiles of the buildings for typical heating season days. The daily consumption profiles for the four sample buildings are shown in Figure 3. A typical behaviour, already observed in other studies [7], is the heat peak at 6 a.m. and an almost constant daily consumption; moreover, the peak decreases as a function of the daily outdoor temperature (i.e. Figures $6 a, 6 b, 6 c$ and $6 d$ ) and of the building efficiency level, which in this case depends on the period of construction.

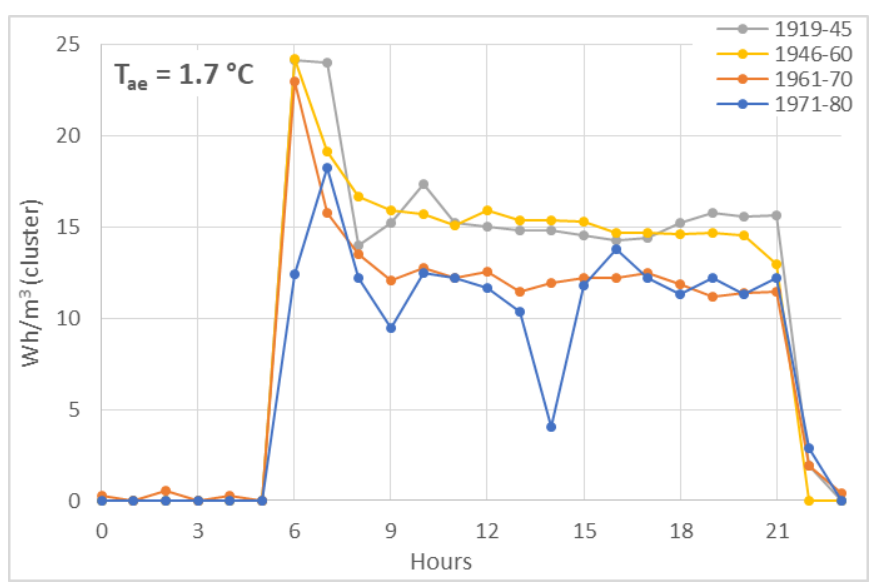

(a) $T_{a e}=1.7^{\circ} \mathrm{C}$ 


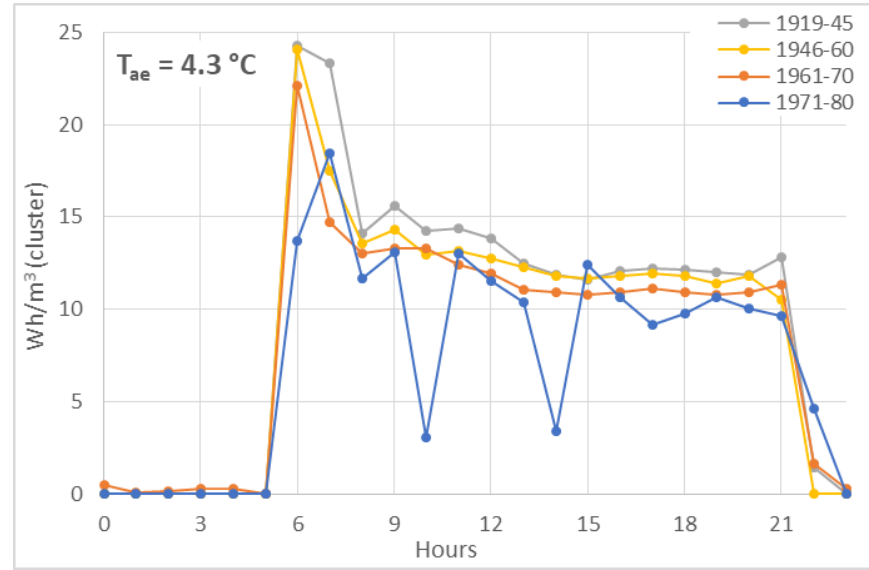

(b) $T_{a e}=4.3^{\circ} \mathrm{C}$

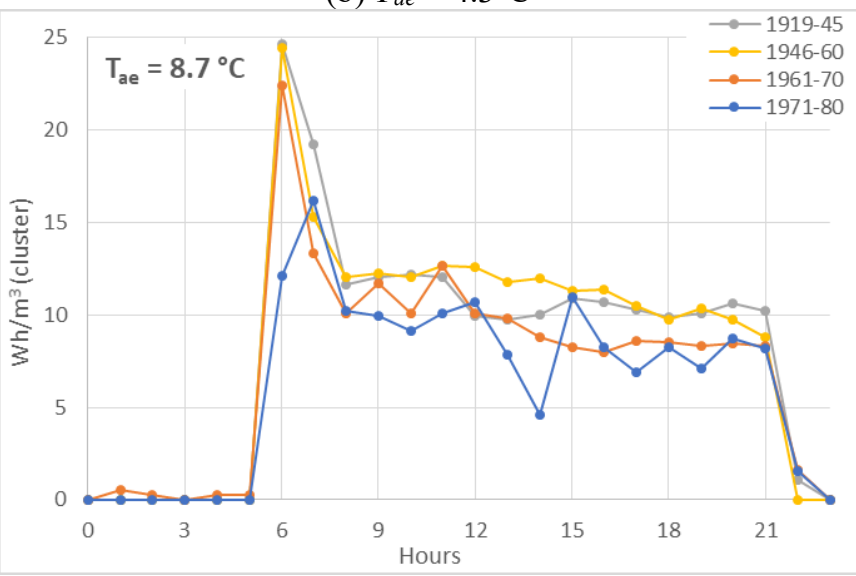

(c) $T_{a e}=8.7^{\circ} \mathrm{C}$

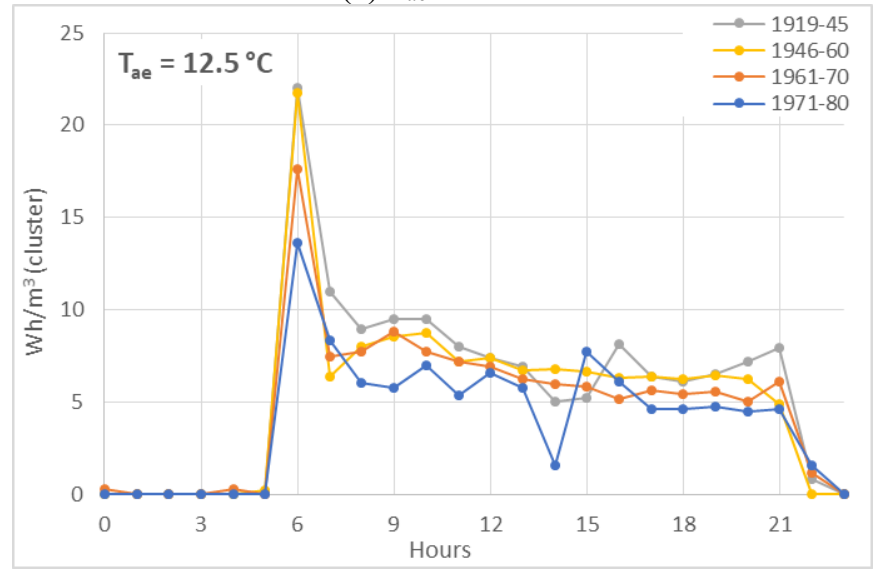

(d) $T_{a e}=12.5^{\circ} \mathrm{C}$

Figure 3. Space heating consumptions $\left(\mathrm{Wh} / \mathrm{m}^{3}\right)$ varying $T_{a e}$

\section{RESULTS AND DISCUSSION}

This section presents the main results obtained from the application of the dynamic urban-scale thermal balance to four typical residential buildings selected according to the period of construction. For comparable results, it was chosen to represent the results with constant infiltration ventilation ( $a \mathrm{ch}$ $\left.=0.5 \mathrm{~h}^{-1}\right)$.

\subsection{Heat flux components}

The heat flow components of the energy balance of residential buildings were investigated to assess the contribution of: the heat flow rate released from the heating system $\left(\Phi_{H}\right)$, the heat flow rate resulting from the internal heat sources $\left(\Phi_{I}\right)$, the heat flow rate obtained from solar radiation $\left(\Phi_{s o l}\right)$, the heat flow rate lost by transmission $\left(\Phi_{T, E}\right.$ and $\left.\Phi_{T, G}\right)$, and the heat flow rate lost by ventilation $\left(\Phi_{V}\right)$.

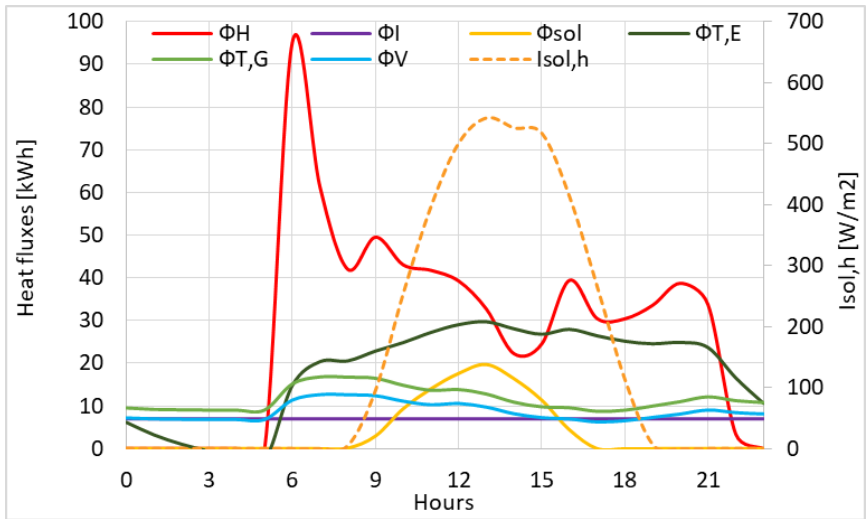

(a) $1919-45$

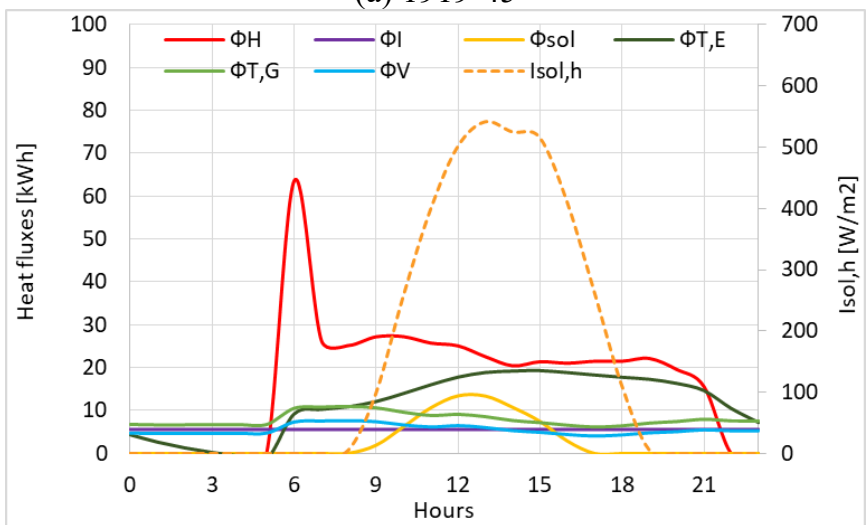

(b) $1946-60$

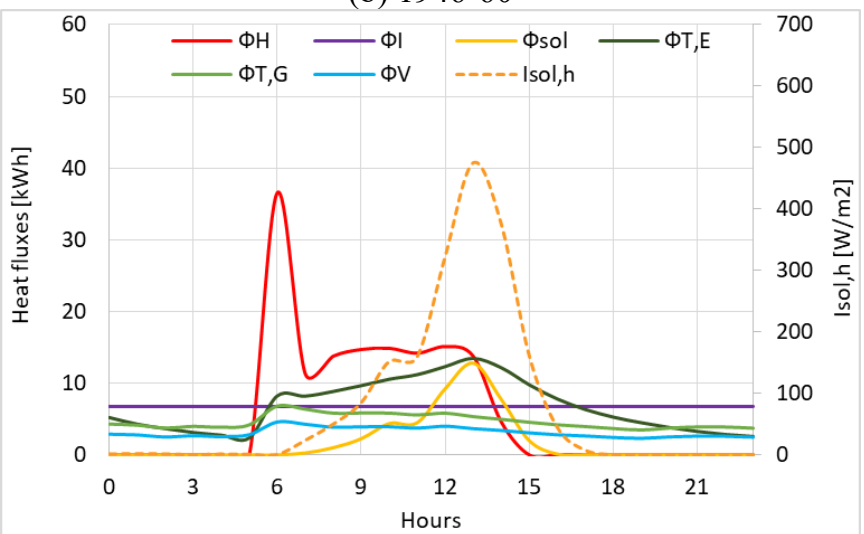

(c) $1961-70$

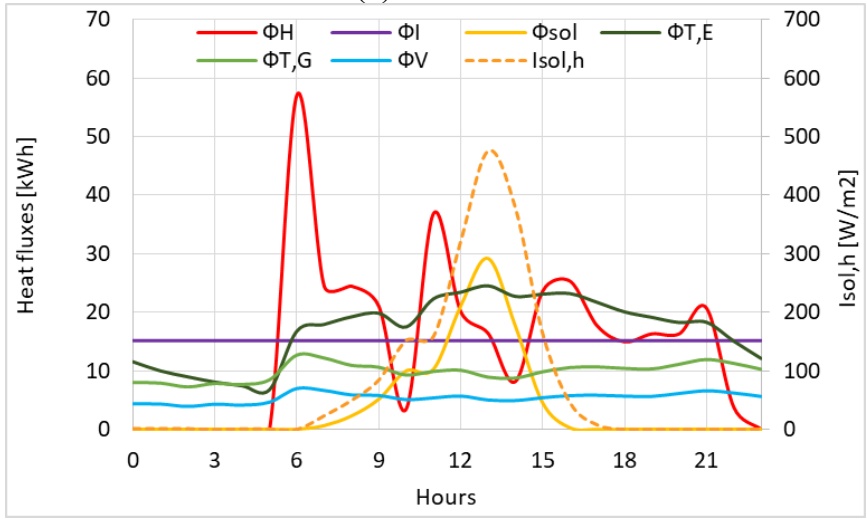

(d) 1971-80

Figure 4. Heat flux components for a typical day: (a)-(b) $22 / 2 / 2014, T_{a e}=6.24^{\circ} \mathrm{C}$; (c)-(d) $24 / 10 / 2013, T_{a e}=16.3^{\circ} \mathrm{C}$ 
Figure 4 shows the results of the energy balance model for a number of constant air changes per hour of $0.5 \mathrm{~h}^{-1}$ over 24 hours for two typical days: February $22^{\text {nd }} 2014$ with $T_{a e}$ equal to $6.24^{\circ} \mathrm{C}$ and October $24^{\text {th }} 2013$ with $T_{a e}$ equal to $16.3^{\circ} \mathrm{C}$. With this type of representation, it is possible to assess the weight of each energy balance component. It is emerged that there is a significant rate of heat flow loss for $\Phi_{T, E}$ and $\Phi_{T, G}$ and the typical behavior of heat realized by the heating system $\Phi_{H}$ with a peak at 6 a.m.

\subsection{Temperatures of the three thermodynamic systems}

The temperatures of the three thermodynamic systems (B, $\mathrm{E}$ and $\mathrm{G}$ ) are shown in Figure 5, with the outside air temperature (in blue) and the solar irradiance (in yellow) on the right. The results are presented for the two typical days that is February $22^{\text {nd }} 2014$ and October $24^{\text {th }} 2013$.

It can emerge that the temperature of the building $T_{B}$ (in green) is quite constant during daytime and nighttime. Thermal comfort conditions, with an internal air temperature of $20 \pm 2{ }^{\circ} \mathrm{C}$, are reached during the day, according to ISO 7730:2005 and EN 16789-1:2019. The three temperatures $T_{B}$, $T_{E}$ and $T_{G}$ are obviously closer in October, because the outdoor air temperature $T_{a e}$ is somewhat warmer and there is less variation between temperatures.

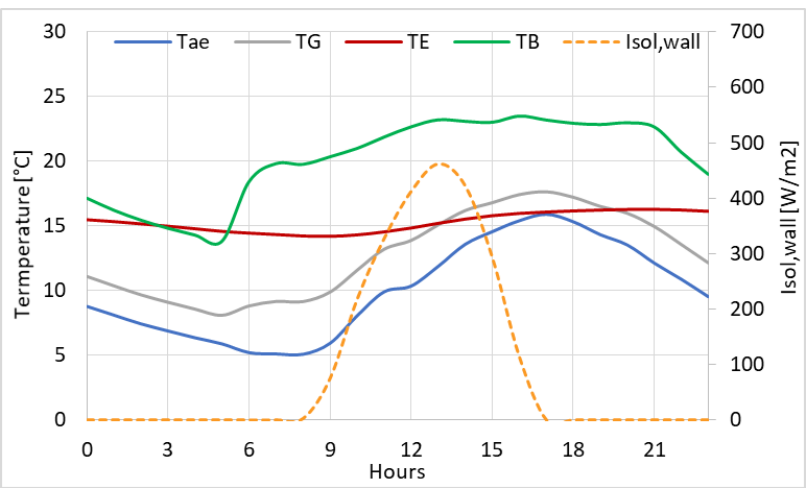

(a) $1919-45$

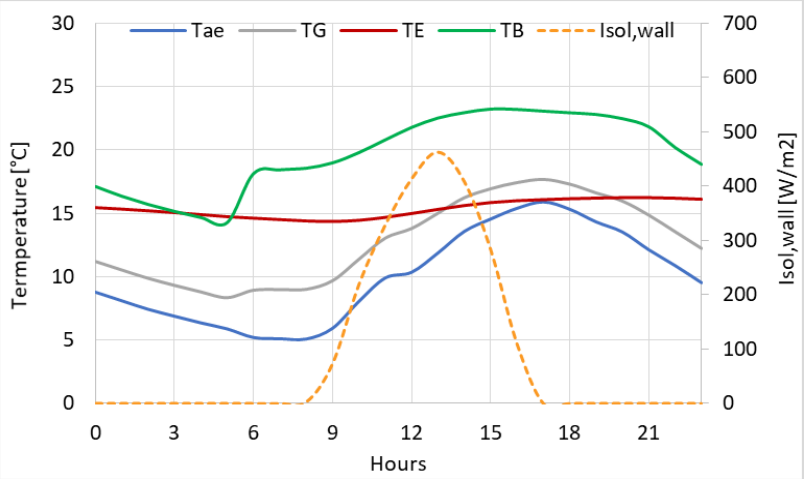

(b) $1946-60$

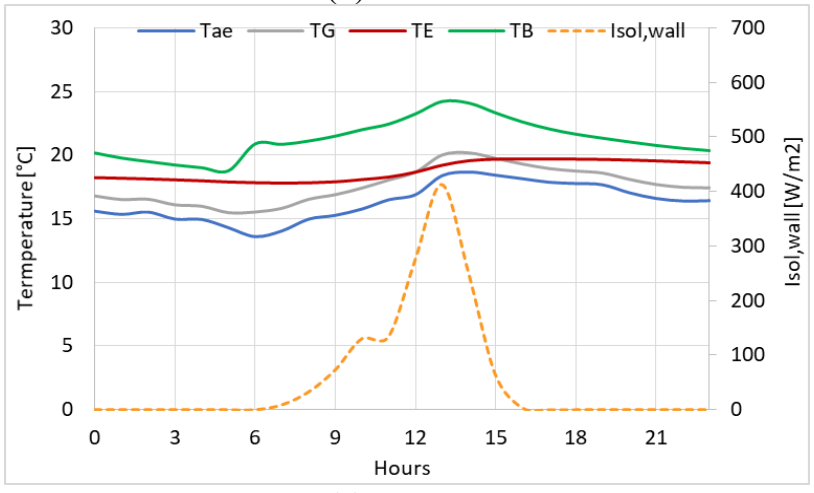

(c) $1961-70$

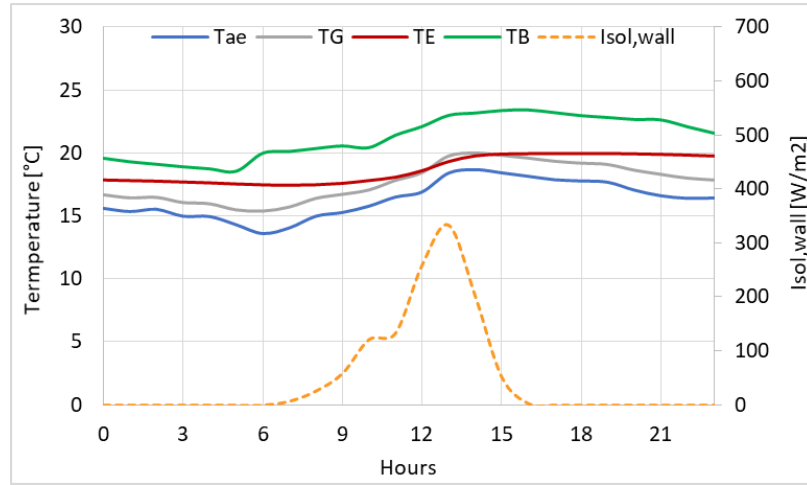

(d) 1971-80

Figure 5. Building temperatures for a typical day: (a)-(b) $22 / 2 / 2014, T_{a e}=6.24^{\circ} \mathrm{C}$; (c)-(d) $24 / 10 / 2013, T_{a e}=16.3^{\circ} \mathrm{C}$

Figure 6 represented the temperature $T_{B}$ for the four selected buildings (with ach $=0.5 \mathrm{~h}^{-1}$ ) and considering different local climate conditions for four typical days: November $26^{\text {th }} 2013$, February $25^{\text {th }} 2014$, March $8^{\text {th }} 2014$, and March $13^{\text {th }} 2014$, with $T_{a e}$ equal to $5.3,9.2,12.5$ and $15.3^{\circ} \mathrm{C}$ respectively.

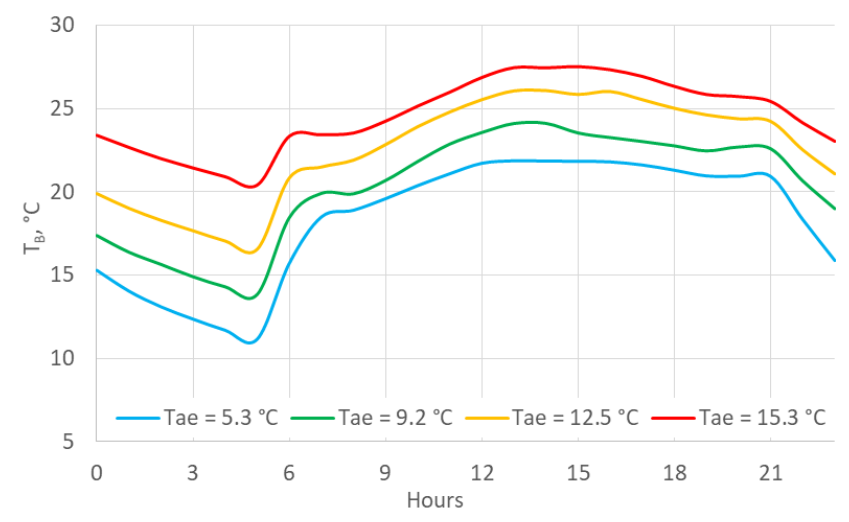

(a) $1919-45$

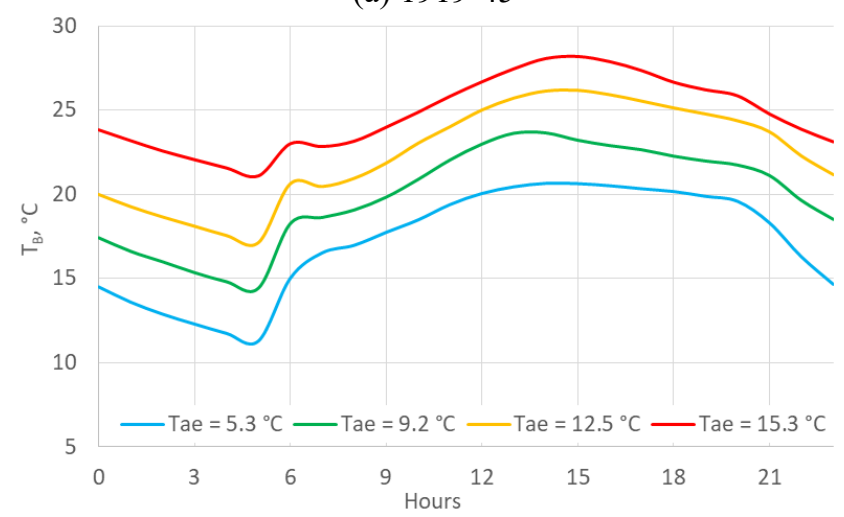

(b) $1946-60$

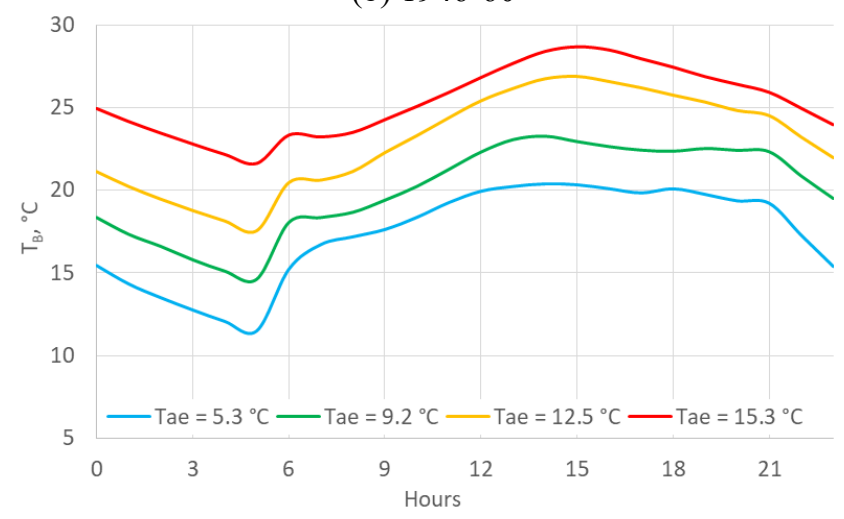

(c) 1961-70 


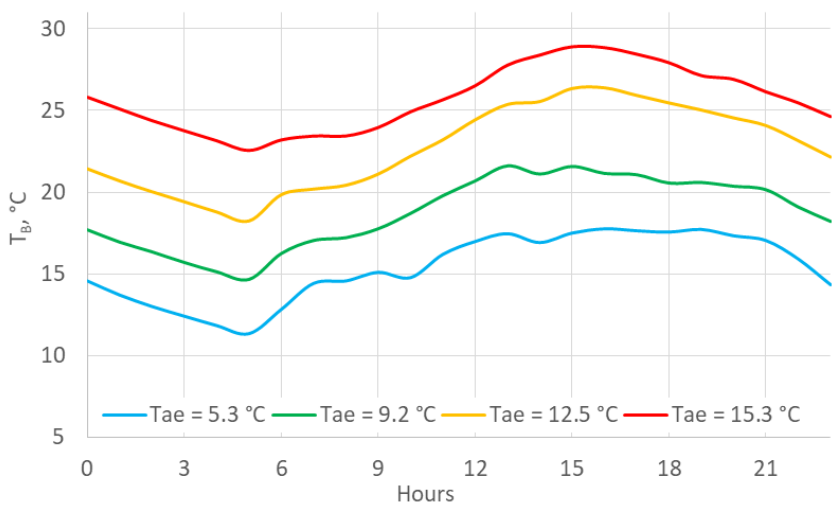

(d) $1971-80$

Figure 6. Building temperatures for four typical days: 26/11/2013, 25/2/2014, 8/3/2013, 13/3/2014

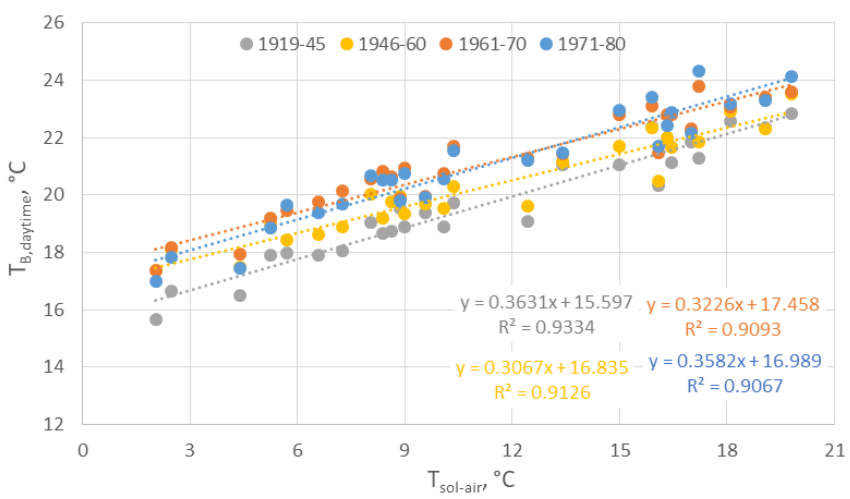

(a) daytime correlations

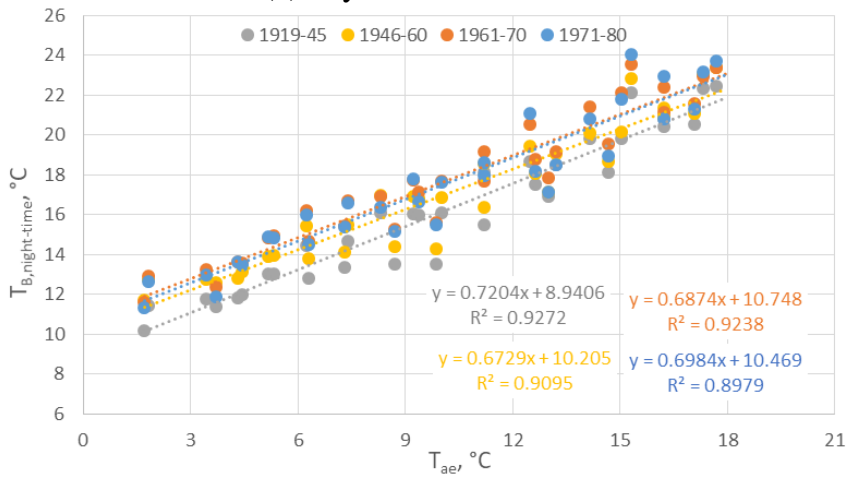

(b) nighttime correlations

Figure 7. Correlations between $T_{B}$ and $T_{\text {sol-air }}$ throughout the daytime, from 6 a.m. to 9 p.m.; $T_{B}$ and $T_{a e}$ during the nighttime, from 10 p.m. to 5 a.m

From this comparison, it is possible to observe that the daytime and nighttime temperatures of $T_{B}$ are quite stable, and this trend depends on the characteristics of the buildings and on the local external climate conditions. Subsequently, the dynamic model was optimized by assuming the obtained correlations between the local climate conditions ( $T_{\text {air }}$ and $T_{\text {sol- }}$ air) -distinguishing daytime and nighttime- and the temperatures of the building, $T_{B}$ (Figure 7).

\subsection{Sensitivity analysis}

In order to define the model and verify that the results were consistent, a sensitivity analysis was carried out on the thermal model in which calculated consumptions were simulated without considering some of the thermal balance components
In particular, the consumptions of the following scenarios were compared:

- S0: with all the components,

- S1: S0 without ventilation dispersions,

- S2: S0 without internal gains and transmitted solar flows and

- S3: S0 without dispersions due to ventilation and internal gains.

Table 7 and Figure 8 show the results of this analysis. The reference scenario is S0 (in red in Figure 9); it can be seen that consumption only increases for all construction periods, if both the internal and solar inputs are removed, while it decreases if the ventilation losses are removed (as it was logical to expect).

Table 7 also shows the percentage shares of increase or decrease in annual consumption according to the period of construction of the buildings under the same local climatic conditions.

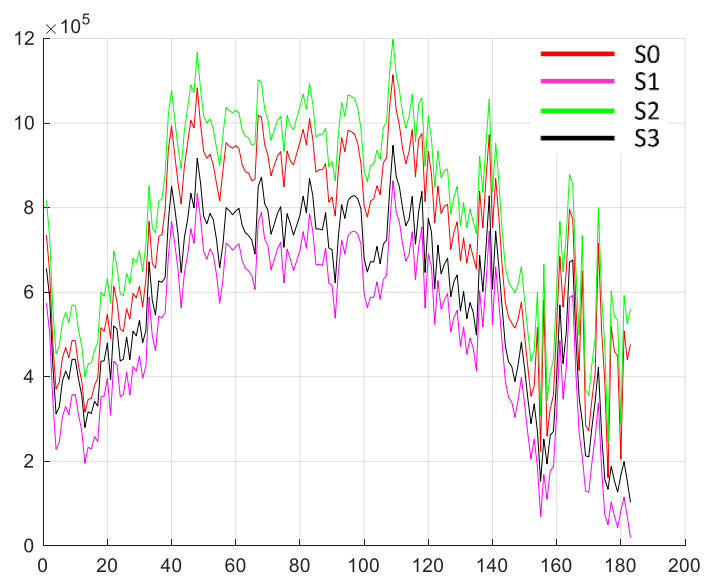

(a) $1919-45$

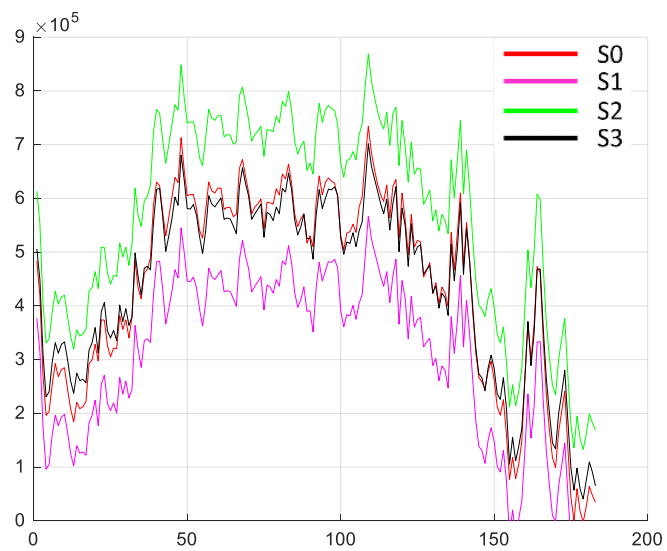

(b) $1946-60$

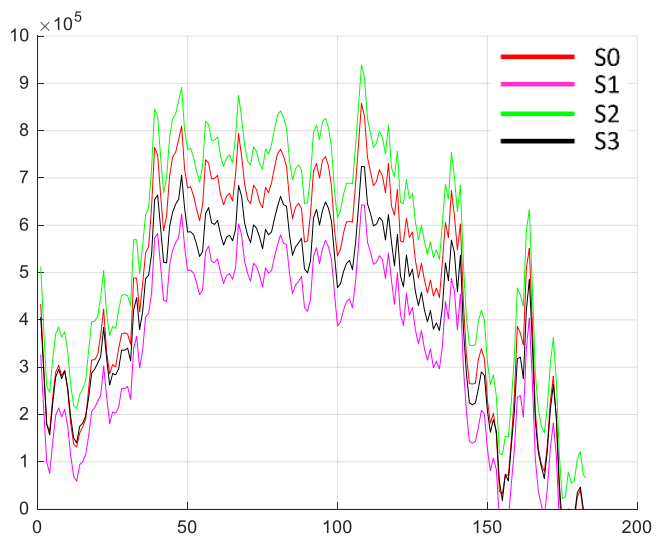

(c) 1961-70 


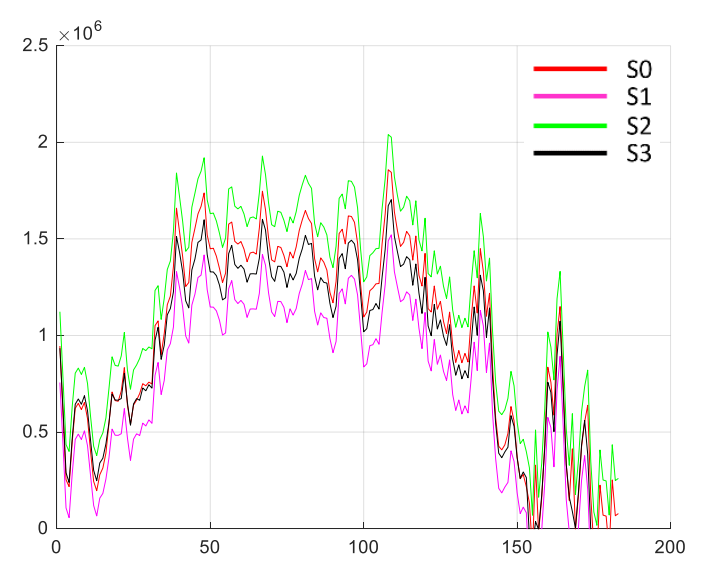

(d) $1971-80$

Figure 8. Building consumptions (in Wh) for the 4 archetypes and the different scenarios

Table 7. Energy consumption variations obtained by changing the heat balance components

\begin{tabular}{cccccccc}
\hline & $\mathbf{1 9 - 4 5}$ & $\mathbf{4 6 - 6 0}$ & $\mathbf{6 1 - 7 0}$ & $\mathbf{7 1 - 8 0}$ & $\phi_{I}$ & $\tau_{G} \cdot I_{\text {Sol }}$ & $m_{a}$ \\
\hline S0 & 1.00 & 1.00 & 1.00 & 1.00 & $\mathrm{Y}$ & $\mathrm{Y}$ & $\mathrm{Y}$ \\
S1 & 0.70 & 0.69 & 0.71 & 0.74 & $\mathrm{Y}$ & $\mathrm{Y}$ & $\mathrm{N}$ \\
S2 & 1.12 & 1.31 & 1.17 & 1.18 & $\mathrm{~N}$ & $\mathrm{Y}$ & $\mathrm{Y}$ \\
S3 & 0.82 & 1.00 & 0.88 & 0.92 & $\mathrm{~N}$ & $\mathrm{Y}$ & $\mathrm{N}$ \\
\hline
\end{tabular}

\subsection{Model validation}

The hourly space heating consumption of the residential buildings was calculated by applying the model with the temperature correlations. The graphs below show the results of the comparison between the simulated and measured consumptions for the 2013-14 heating season for the four selected buildings.

Figure 9 shows the results of a comparison between the simulated and measured daily thermal consumption. A very good accuracy can be observed for buildings built in the 194945, 1946-60 and 1961-70 periods. The accuracy decreases for buildings constructed in the $1971-80$ period. This problem arose also because this sample is composed of a limited number of buildings and further investigations will be made in the future to optimize the precision of the model.

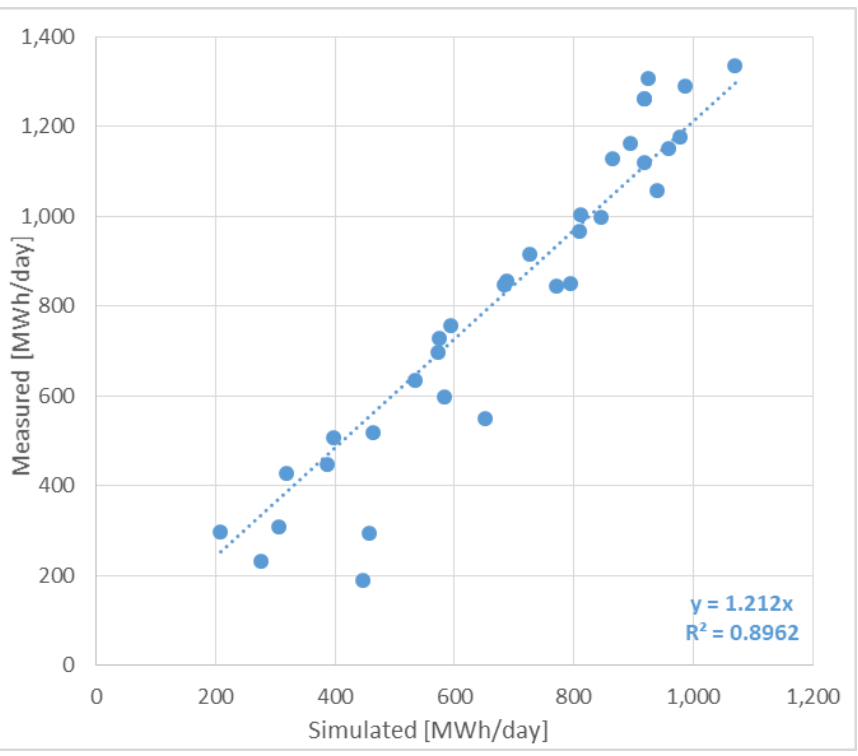

(a) $1919-45$

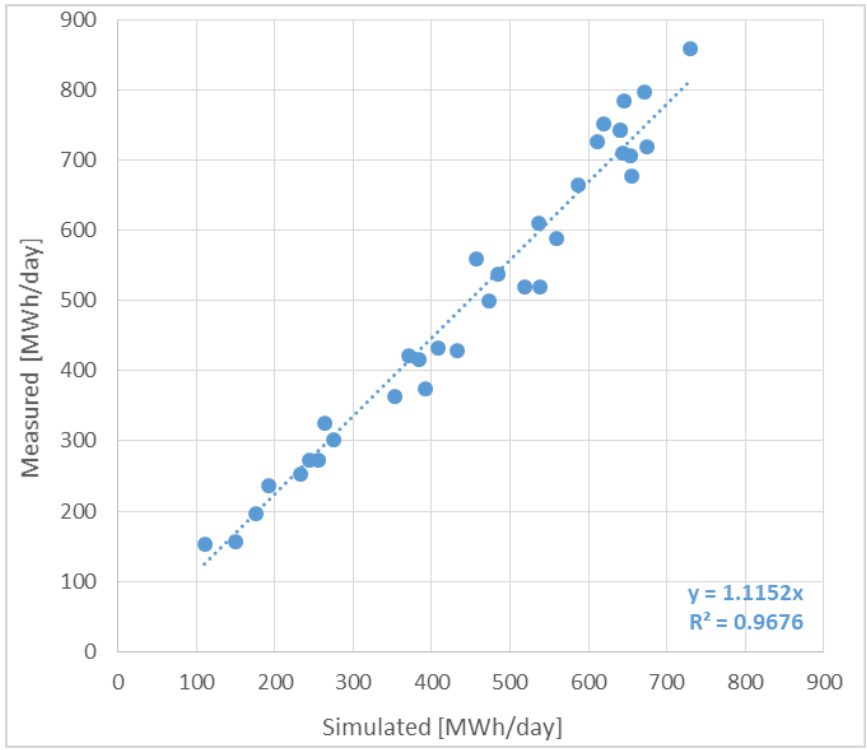

(b) $1946-60$

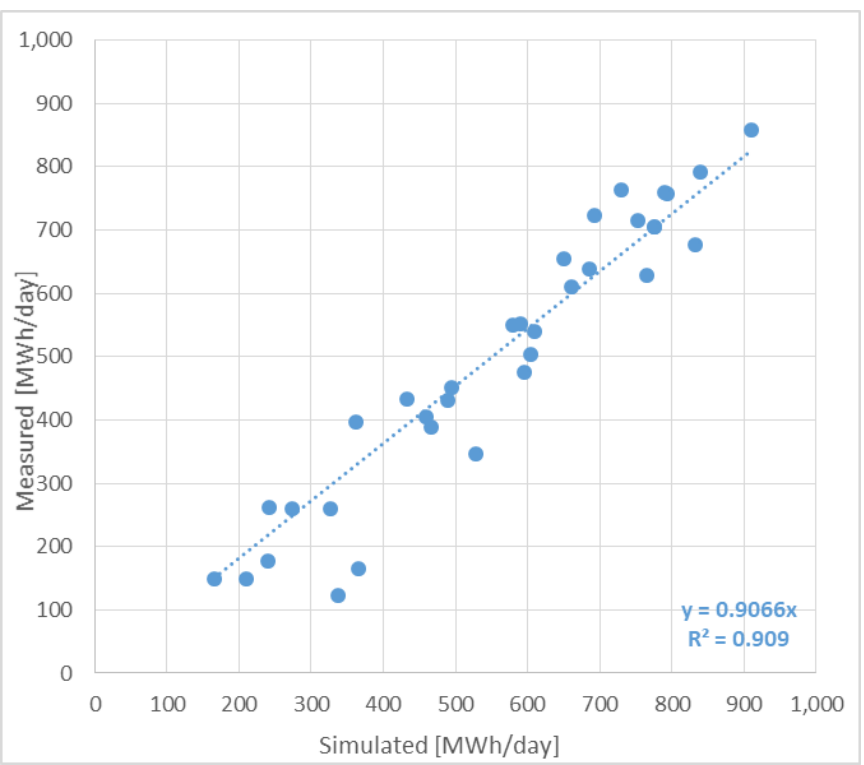

(c) 1961-70

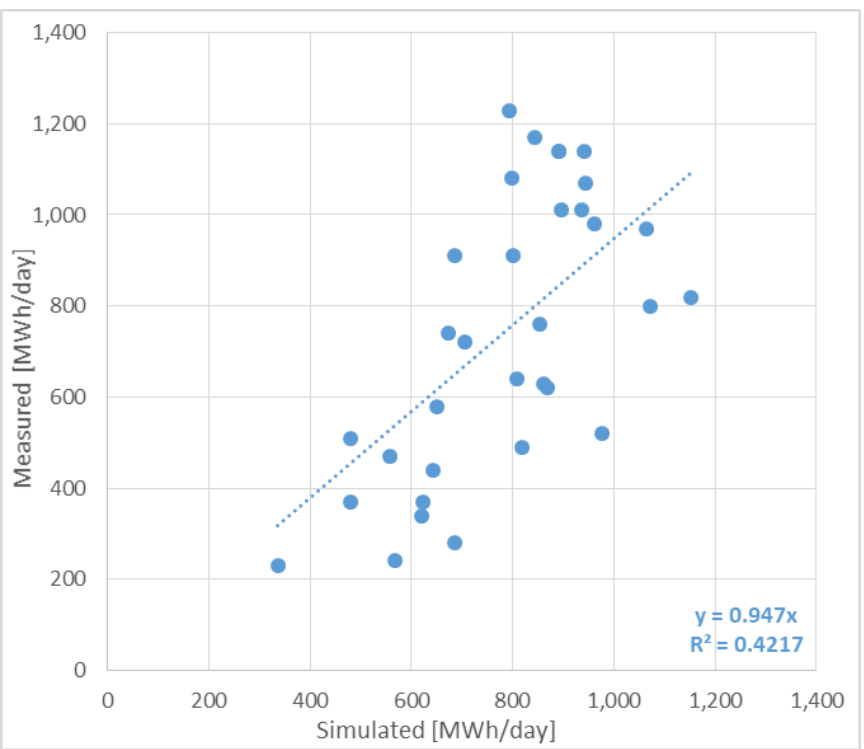

(d) $1971-80$

Figure 9. Comparison between the simulated and measured space heating consumptions 


\section{CONCLUSIONS}

The objective of this work has been to develop an engineering model that can be used for the evaluation of the heating consumption of buildings in European cities. This model should be able to use existing spatial databases, and, for this reason, the model was associated with a GIS tool. Starting from building scale consumption models, the energy-balance equations have been simplified so that data can be found in the technical map for all buildings in a city. In addition, variables have been calculated so that the urban features around each building, that influence its consumption, can be described.

The energy-balance model was initially applied using a spreadsheet to a limited group of buildings A specific code was then implemented using thermal-electrical analogy with a scientific computation and simulation software in order to extend the use of the model to all the buildings considered in the analysis. The results of this work show that the model works very well with buildings that have high consumptions. However, the accuracy of the model decreases for newer buildings due also to a smaller number of buildings with these characteristics.

The thermal-electrical analogy is suitable to manage a large amount of data with less time-consuming, to evaluate the specific contribution of the heat flows, and compare the heat flows among the elements of the systems.

Moreover, this analogy can help to solve the energy balance if new elements are added to the system or if reference days are considered and the system is assumed to work under periodic in steady state conditions.

\section{REFERENCES}

[1] Rosenow, J., Cowart, R., Bayer, E., Fabbri, M. (2017). Assessing the European Union's energy efficiency policy: Will the winter package deliver on 'Efficiency First'? Energy Research \& Social Science, 26: 72-79. https://doi.org/10.1016/j.erss.2017.01.022

[2] Hedegaard, R.E., Kristensen, M.H., Pedersen, T.H., Brun, A., Petersen, S. (2019). Bottom-up modelling methodology for urban-scale analysis of residential space heating demand response. Applied Energy, 242: 181-204. https://doi.org/10.1016/j.apenergy.2019.03.063

[3] Mutani, G., Todeschi, V. (2019). An urban energy atlas and engineering model for resilient cities. International Journal of Heat and Technology, 37(4): 936-947. https://doi.org/10.18280/ijht.370402

[4] Mutani, G., Todeschi, V. (2020). Building energy modeling at neighborhood scale. Energy Efficiency. https://doi.org/10.1007/s12053-020-09882-4

[5] Abbasabadi, N., Ashayeri, M. (2019). Urban energy use modeling methods and tools: A review and an outlook. Building and Environment, 161: 106270. https://doi.org/10.1016/j.buildenv.2019.106270

[6] Chen, Y., Hong, T., Piette, M.A. (2017). Automatic generation and simulation of urban building energy models based on city datasets for city-scale building retrofit analysis. Applied Energy, 205: 323-335. https://doi.org/10.1016/j.apenergy.2017.07.128

[7] Mutani, G., Todeschi, V., Beltramino, S. (2020). Energy consumption models at urban scale to measure energy resilience. Sustainability, 12(14): 5678. https://doi.org/10.3390/su12145678
[8] Mutani, G., Todeschi, V., Matsuo, K. (2019). Urban heat island mitigation: A GIS-based model for Hiroshima. Instrumentation Mesure Métrologie, 18(4): 323-335. https://doi.org/10.18280/i2m.180401

[9] Chen, Q., Fu, R.H., Xu, Y.C. (2014). Electrical circuit analogy for heat transfer analysis and optimization in heat exchanger networks. Applied Energy, 139: 81-92. https://doi.org/10.1016/j.apenergy.2014.11.021

[10] Fracastoro, G.V., Mutani, G., Perino, M. (2002). Experimental and theoretical analysis of natural ventilation by windows opening. Energy and Buildings, 34(8): $\quad 817-827$. https://doi.org/10.1016/S03787788(02)00099-3

[11] Alhamwi, A., Medjroubi, W., Vogt, T., Agert, C. (2017). GIS-based urban energy systems models and tools: Introducing a model for the optimisation of flexibilisation technologies in urban areas. Applied Energy, 191: 1-9. https://doi.org/10.1016/j.apenergy.2017.01.048

[12] Capizzi, G., Lo Sciuto, G., Cammarata, G., Cammarata, M. (2017). Thermal transient simulations of a building by a dynamic model based on thermal-electrical analogy: Evaluation and implementation issue. Applied Energy, 199: 323-334. https://doi.org/10.1016/j.apenergy.2017.05.052

[13] Fraisse, G., Viardot, C., Lafabrie, O., Achard, G. (2002). Development of a simplified and accurate building model based on electrical analogy. Energy \& Buildings, 34(10): 1017-1031. https://doi.org/10.1016/S03787788(02)00019-1

[14] Robinson, D., Haldi, F., Kampf, J.H., Leroux, P., Perez, D., Rasheed, A., Wilke, U. (2009). CITYSIM: Comprehensive micro-simulation of resource flows for sustainable urban planning. Eleventh International IBPSA Conference, Glasgow, Scotland.

[15] Boghetti, R., Fantozzi, F., Kämpf, J.H., Mutani, G., Salvadori, G., Todeschi, V. (2019) Building energy models with morphological urban-scale parameters: A case study in Turin. In Book of Proceedings of BSA 2019, pp. 131-139.

[16] AA. VV. - TABULA Typology Approach for Building Stock Energy Assessment - Webtool, http://webtool.building-typology.eu/\#bm, accessed on January 5th 2020 .

[17] Mutani, G., Gabrielli, C., Nuvoli, G. (2020). Energy performance certificates analysis in piedmont region (IT). A New Oil Field Never Exploited Has Been Discovered. Tecnica Italian-Italian Journal of Engineering Science, 64(1): 71-82. https://doi.org/10.18280/ti-ijes.640112

\section{NOMENCLATURE}

ach Number of air changes per hour, $\mathrm{h}^{-1}$

A area, $\mathrm{m}^{2}$

b correction factor for unconditioned spaces

c specific heat capacity, $\mathrm{Jkg}^{-1} \mathrm{~K}^{-1}$

C heat (thermal) capacity, $\mathrm{JK}^{-1}$

DH district heating, -

EP energy performance index, $\mathrm{kWh} \mathrm{m}^{-2} \mathrm{~K}^{-1}$

EPC Energy performance certificate

F reduction/view factor, -

$\mathrm{h}$ surface coefficient of heat transfer, $\mathrm{Wm}^{-2} \mathrm{~K}^{-1}$

H/W urban canyon height-to-width ratio, - 
I solar irradiance, $\mathrm{Wm}^{-2}$

$\mathrm{R}$ thermal resistance, $\mathrm{m}^{2} \mathrm{KW}^{-1}$

$\mathrm{S}$ floor surface, $\mathrm{m}^{2}$

SVF sky view factor, -

$\mathrm{t}$ time, $\mathrm{s}$

$\mathrm{T}$ temperature, ${ }^{\circ} \mathrm{C}$ or $\mathrm{K}$

TS thermodynamic system

$\mathrm{U}$ thermal transmittance, $\mathrm{Wm}^{-2} \mathrm{~K}^{-1}$

V volume, $\mathrm{m}^{3}$

\section{Greek symbols}

$\alpha \quad$ absorption coefficient of solar radiation, -

$\varepsilon \quad$ emissivity

$\eta \quad$ system efficiency for space heating, -

$\rho$ density, $\mathrm{kgm}^{-3}$

$\lambda$ conductivity, $\mathrm{Wm}^{-1} \mathrm{~K}^{-1}$

$\xi \quad$ shadow quota, -

$\tau$ total solar energy transmittance, -

$\Phi$ heat flow rate, thermal power, W $\psi \quad$ solar height, ${ }^{\circ}$

\section{Subscripts}

ae external air

B building

E envelope

e external

g gross

G glazing

$\mathrm{H}$ heating

int internal

$\mathrm{k} \quad$ building element

n net

se external surface

sol solar

$\mathrm{T}$ transmission

$\mathrm{v} \quad$ ventilation

w windows 